\title{
Macropodumines D and E, Two Novel Alkaloids With Unusual \\ Skeletons From Daphniphyllum macropodum Miq.
}

Zhen-Yu Li ${ }^{\dagger}$, Ping Chen ${ }^{\dagger}$, Hong-Gui Xu ${ }^{\ddagger}$, Yi-Ming Yang ${ }^{\dagger}$, Shu-Ying Peng ${ }^{\dagger}$, Zhong-Zhen Zhao ${ }^{\ddagger}$ and Yue-Wei Guo ${ }^{*}{ }^{\dagger}$

Shanghai Institute of Material Medica, Chinese Acedemy of Science, Shanghai 201203, People's Republic of China, and School of Chinese Medicine, Hong Kong Baptist University, Kowloon Tong, Hong Kong 999077 Corresponding author, Phone: (+86) 21-50803318, Fax: (+86) 21-50807088. Email address: ywguo@mail.shcnc.ac.cn

\section{Index}

$\begin{array}{ll}\text { Experimental Section } & \text { S2 }\end{array}$

HR-ESIMS spectrum of macropodumine D (1) S3-S4

${ }^{1} \mathrm{H}$ NMR spectrum of macropodumine D (1) $\left(600 \mathrm{MHz}, \mathrm{CDCl}_{3}\right) \quad$ S5-S6

${ }^{13} \mathrm{C}$ NMR spectrum of macropodumine D (1) $\left(100 \mathrm{MHz}, \mathrm{CDCl}_{3}\right) \quad$ S7-S8

${ }^{1} \mathrm{H}-{ }^{1} \mathrm{H}$ COSY spectra of macropodumine D (1) S9-S10

HSQC spectra of macropodumine D (1) S11

HMBC spectra of macropodumine D (1) S12-S13

ROESY spectra of macropodumine D (1) S14-S15

HR-ESIMS spectrum of macropodumine E (2) S16-S17

${ }^{1} \mathrm{H}$ NMR spectrum of macropodumine E (2) $\left(600 \mathrm{MHz}, \mathrm{CDCl}_{3}\right) \quad \mathrm{S} 18$

${ }^{13} \mathrm{C}$ NMR spectrum of macropodumine E (2) $\left(100 \mathrm{MHz}, \mathrm{CDCl}_{3}\right) \quad$ S19-S20

${ }^{1} \mathrm{H}-{ }^{1} \mathrm{H}$ COSY spectra of macropodumine E (2) S21-S22

HSQC spectra of macropodumine E (2) S23-S24

$\begin{array}{ll}\text { HMBC spectra of macropodumine E (2) } & \text { S25-S27 }\end{array}$

$\begin{array}{lr}\text { ROESY spectra of macropodumine E (2) } & \text { S28-S29 }\end{array}$

\footnotetext{
${ }^{\dagger}$ Shanghai Institute of Material Medica

\$ Hong Kong Baptist University.
} 


\section{Experimental Procedure}

General: Commercial silica gel (Qing Dao Hai Yang Chemical Group Co., 200-300 mesh) and amino silica gel (Merck, LiChroprep $\mathrm{NH}_{2} 40-63 \mu \mathrm{m}$ ) was used for column chromatography. Precoated silica gel plates (Yan Tai Zi Fu Chemical Group Co., G60 F-254) were used for analytical thin-layer chromatography (TLC). The NMR spectra were recorded at $293 \mathrm{~K}$ on a Varian Mercury-600 and 400 spectrometers $(600 \mathrm{MHz}$ for ${ }^{1} \mathrm{H}$ and $100 \mathrm{MHz}$ for ${ }^{13} \mathrm{C}$ ). Chemical shifts are reported with the residual $\mathrm{CHCl}_{3}$ $\left(\delta_{\mathrm{H}} 7.26 \mathrm{ppm}\right)$ as the internal standard for ${ }^{1} \mathrm{H}$ NMR spectrometry, and $\mathrm{CDCl}_{3}\left(\delta_{\mathrm{C}} 77.0\right.$ ppm) for ${ }^{13} \mathrm{C}$ NMR spectrometry. ${ }^{1} \mathrm{H}$ and ${ }^{13} \mathrm{C}$ NMR assignments were supported by ${ }^{1} \mathrm{H}-{ }^{1} \mathrm{H}$ COSY, HSQC, HMBC and ROESY experiments. Optical Rotations were measured on a PERKIN-ELMER 341 polarimeter at the sodium D-line. Infrared spectra were recorded on a Nicolet Magna FT-IR 750 spectrophotometer; peaks are reported in $\mathrm{cm}^{-1}$. The mass spectra and high resolution mass spectra were performed on a Q-TOF Micro LC-MS-MS mass spectrometer.

Plant material: The barks and leaves of Daphniphyllum macropodum Miq. were collected in the Emei Mountain, Sichuan Province of P. R. China, in April, 2005, and identified by Professor Honggui Xu of Hongkong Baptist University. A voucher specimen is available for inspection at the Herbarium of the Institute of Matria Medica, Chinese Academy of Science.

Extraction and isolation: The air-dried powdered leaves and barks $(1.4 \mathrm{Kg})$ of $D$. macropodum were extracted with 95\% EtOH (three times, each 7 day) at room temperature. Evaporation of the solvent gave a residue, which was suspended in water (1 L) and adjusted to $\mathrm{pH} 4-5$ with $2 \mathrm{~N} \mathrm{H}_{2} \mathrm{SO}_{4}$. The acidic mixture was defatted with EtOAc $(3 \times 1 \mathrm{~L})$, and the aqueous layer was basified to $\mathrm{pH} 9-10$ with saturated $\mathrm{NaCO}_{3}$, and then extracted with $\mathrm{CHCl}_{3}(3 \times 1 \mathrm{~L})$ to yield the crude alkaloids $(7.1 \mathrm{~g})$. The crude alkaloids were subjected to silica gel chromatography eluted with a $\mathrm{CHCl}_{3} / \mathrm{CH}_{3} \mathrm{OH} / \mathrm{Et}_{2} \mathrm{NH}$ (50:1:0.1 to 1:1:0.1) gradient to give fractions Fr. 1 to Fr. 10. Further amino silica gel chromatography $\left(\mathrm{CHCl}_{3} / \mathrm{CH}_{3} \mathrm{OH}, 33: 1\right)$ on Fr. 7 and Fr. 2 afforded macropodumines D (1) (5.1 mg) and E (2) (9.3mg), respectively. 
HR-ESIMS spectrum of Macropodumine D (1)
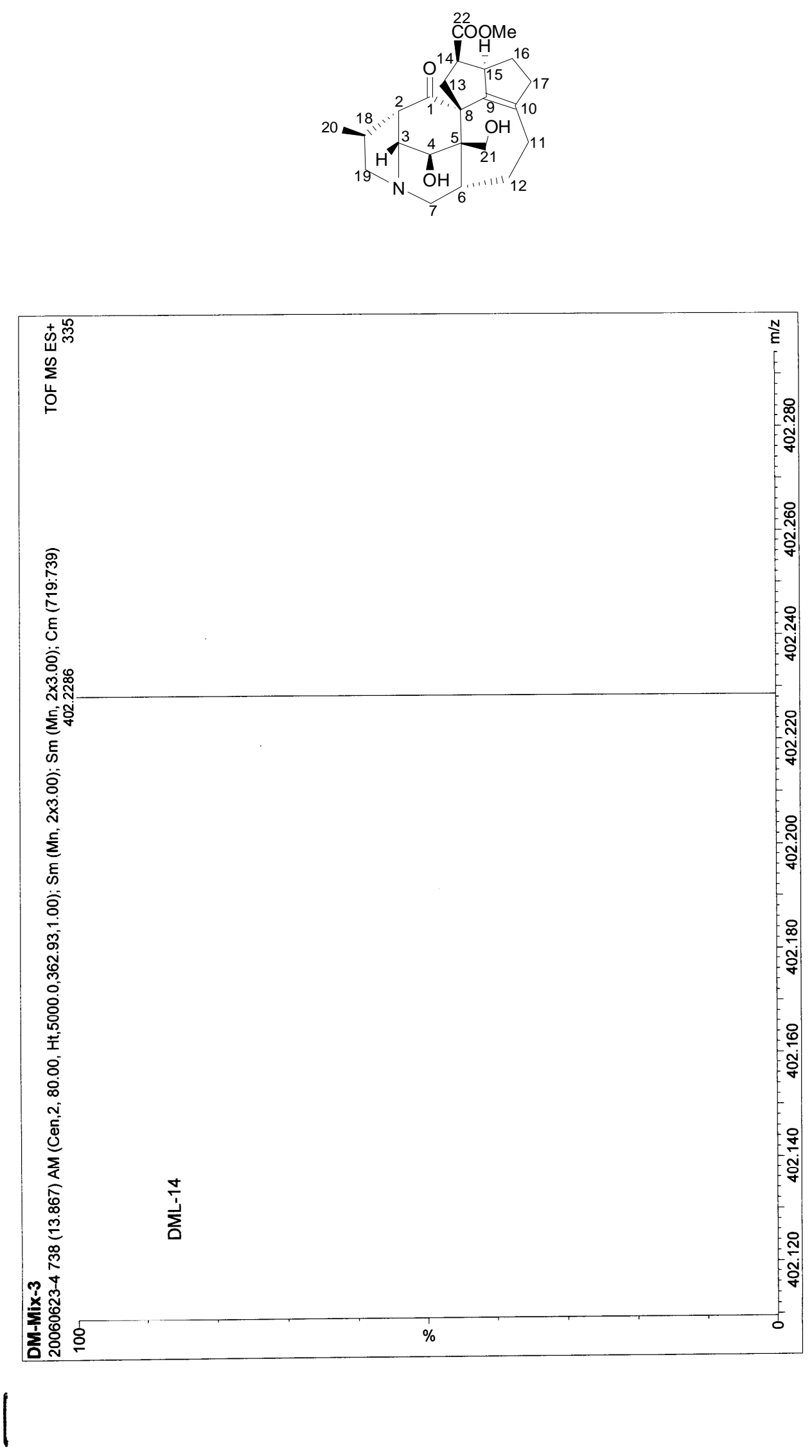
HR-ESIMS spectrum of Macropodumine D (1) (Continued)

Elemental Composition Report

Page

Tolerance $=20.0$ PPM / DBE: $\min =-1.5, \max =50.0$

Isotope cluster parameters: Separation $=1.0$ Abundance $=1.0 \%$

Monoisotopic Mass, Odd and Even Electron lons

13 formula(e) evaluated with 1 results within limits (up to 20 closest results for each mass)

DM-Mix-3 $20060623-4$ 738 (13.867) AM (Cen, 2, 80.00, Ht,5000.0,362.93,1.00); Sm (Mn, 2x3.00); Sm (Mn, 2×3.00); Cm (719:739) $100-402.2286$

$\underset{335}{\text { TOF MS ES+ }}$
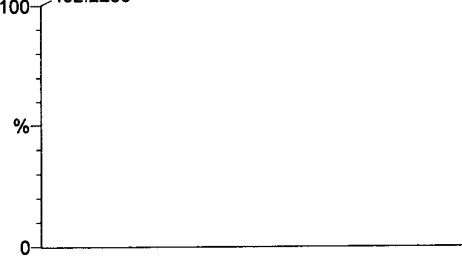

402.229

Minimum:

Maximum:

$200.0 \quad 20.0 \quad 50.0$

Mass Mas ma PBM

$\begin{array}{llllllllll}402.2286 & 402.2280 & 0.6 & 1.4 & 8.5 & 1 & \text { C23 } & \text { H32 } & \mathrm{N} & 05\end{array}$


${ }^{1} \mathrm{H}$ NMR spectrum of Macropodumine D (1) in $\mathrm{CDCl}_{3}$

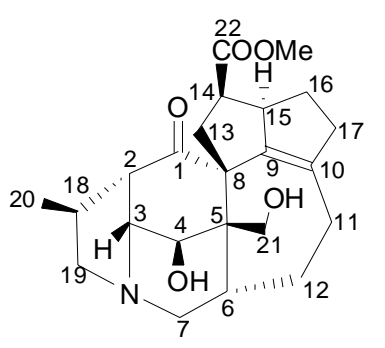

1699

1.2E
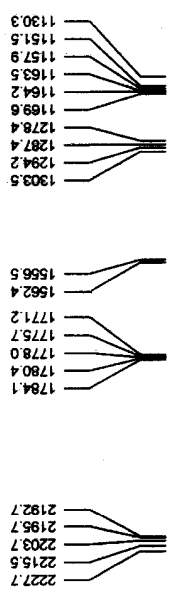

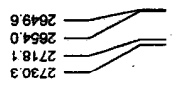

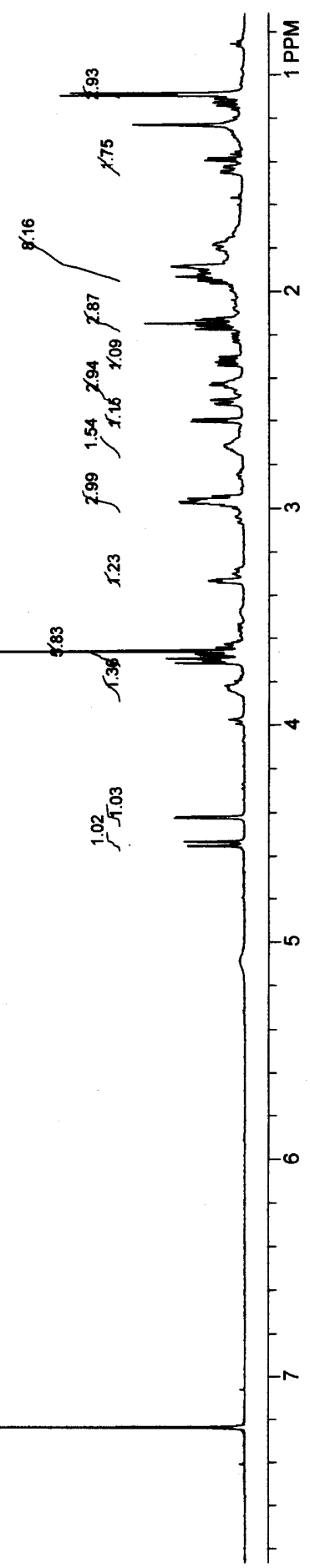


${ }^{1} \mathrm{H}$ NMR spectrum of Macropodumine D (1) in $\mathrm{CDCl}_{3}$ (Enlarged)
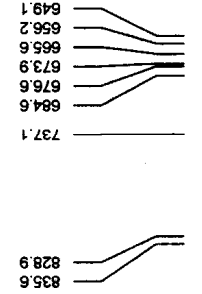

$89901-$
$\angle 0 \angle 01$

$\angle 0 \angle 01=$

$2801 \div$

$8 \mathrm{z}+\mathrm{tl}$

S'ISLI

6.LSL

ב

2.69l

6.9LLL

$z ! L z \mid=$

$8<2<1$

D.LBZL

(

$\varepsilon \cdot 10 \varepsilon h$

s.08et

'88eb

$\varepsilon s 6 \varepsilon 1$

test

o'sebt

zosi $=$

ZISI

atisi -

cosst

$6 \varepsilon 94$

L $994 L$

$\angle G \angle L L$

$8 \angle 2 L \longrightarrow$

†

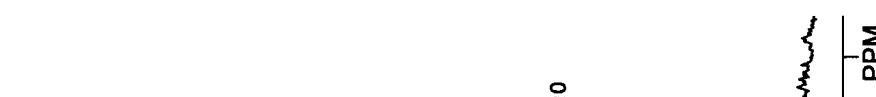

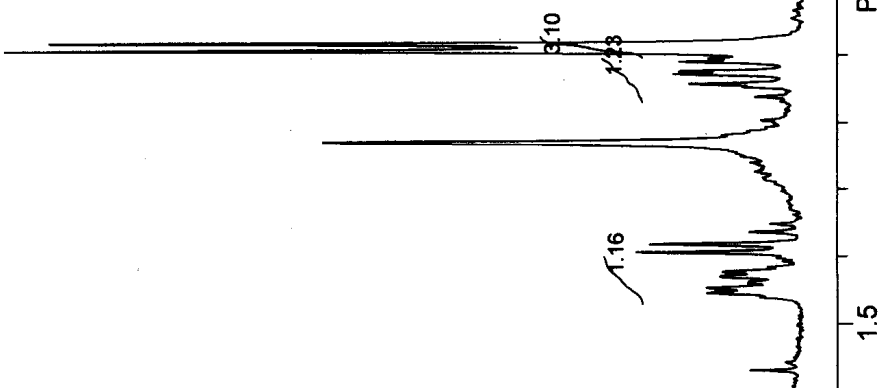

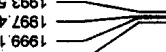

: $6061=$

$\hat{\xi}$
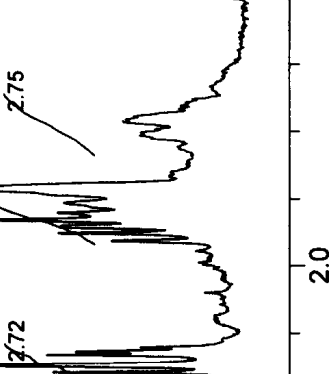

$\frac{\sum}{2}$

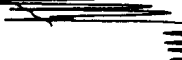

3
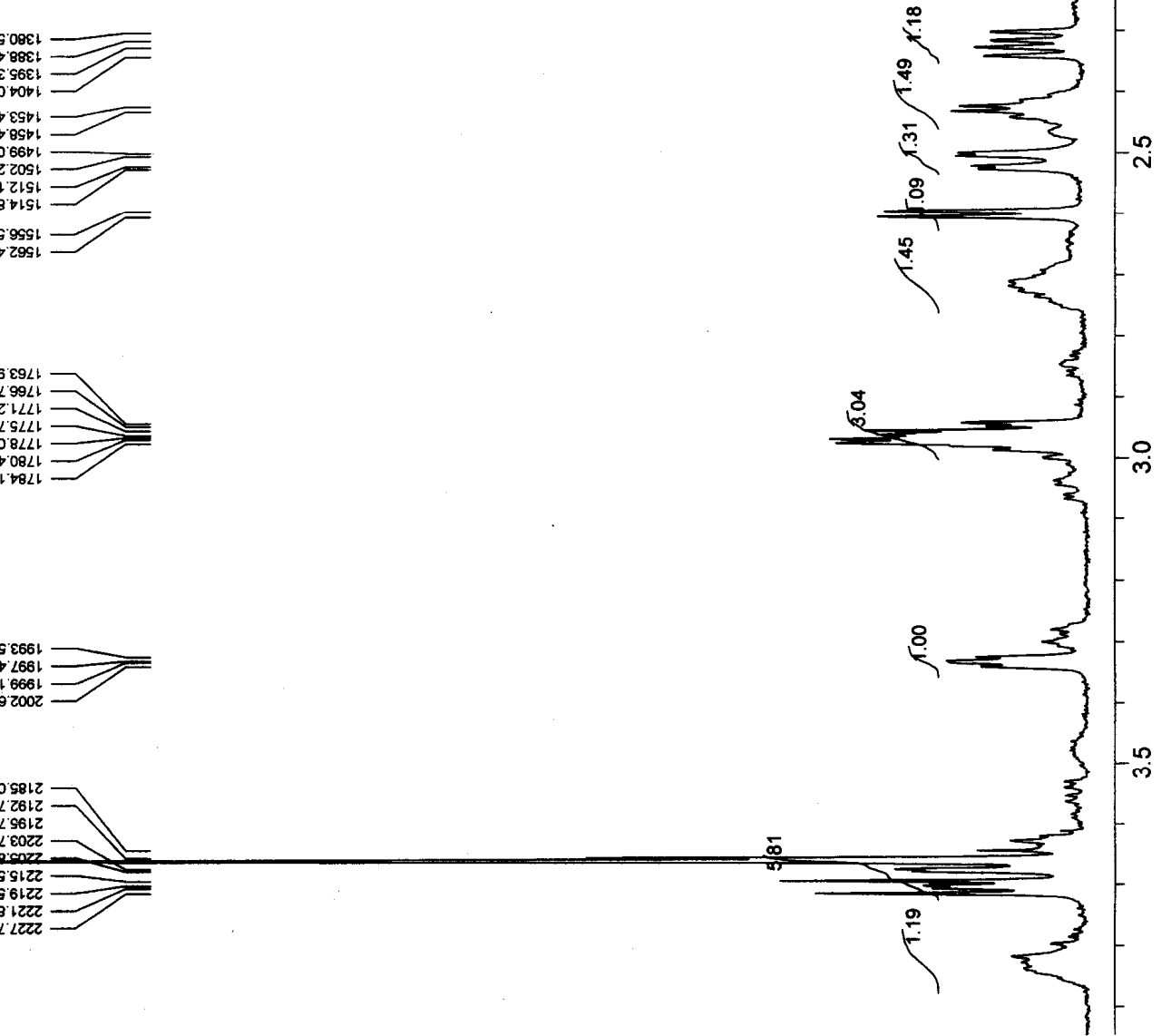
${ }^{13} \mathrm{C}$ NMR spectrum of Macropodumine D (1) in $\mathrm{CDCl}_{3}$
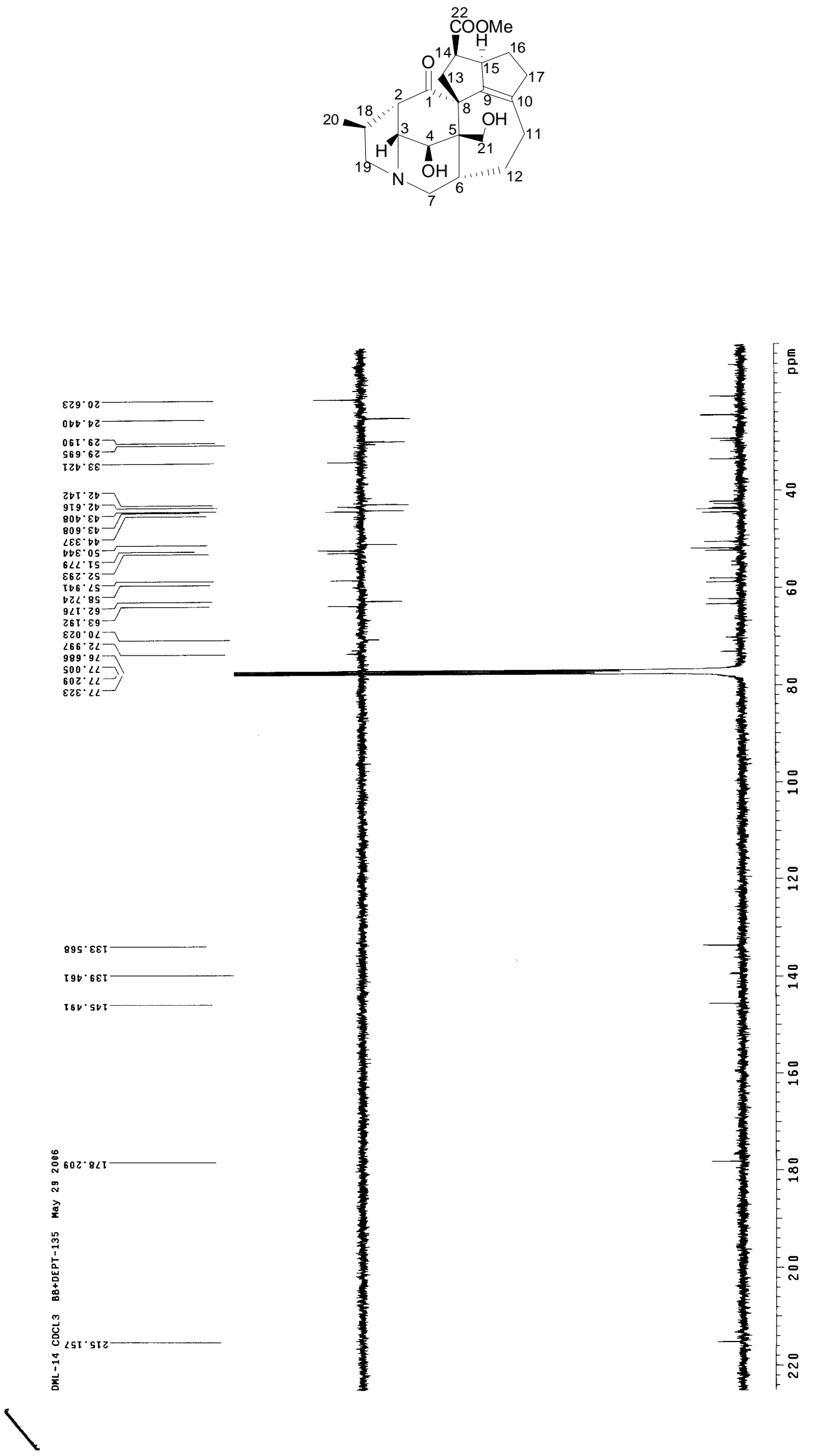

7 
${ }^{13} \mathrm{C}$ NMR spectrum of Macropodumine D (1) in $\mathrm{CDCl}_{3}$ (Enlarged)
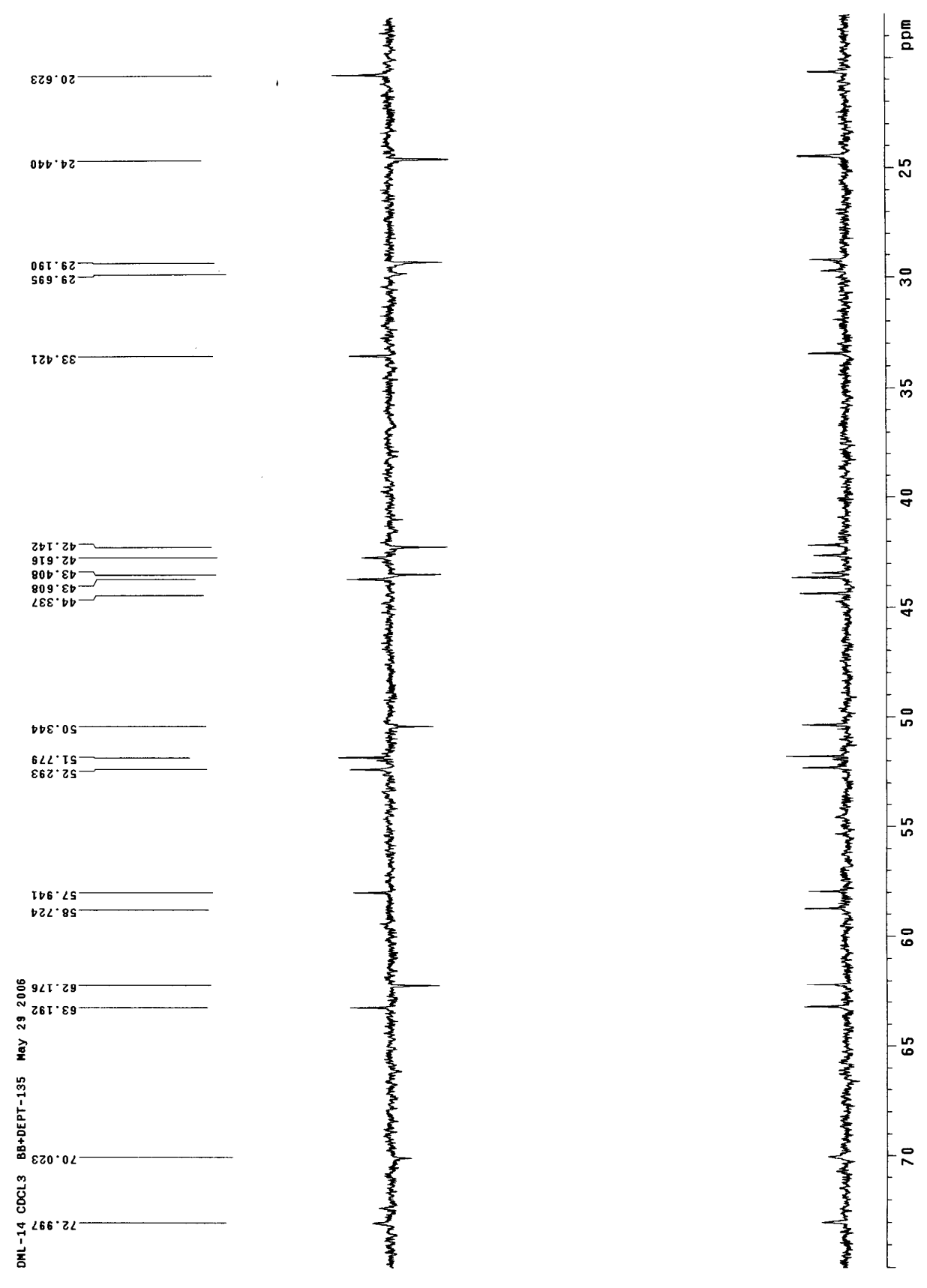
${ }^{1} \mathrm{H}-{ }^{1} \mathrm{H}$ COSY spectrum of Macropodumine D (1) in $\mathrm{CDCl}_{3}$

$$
\text { 20 }
$$

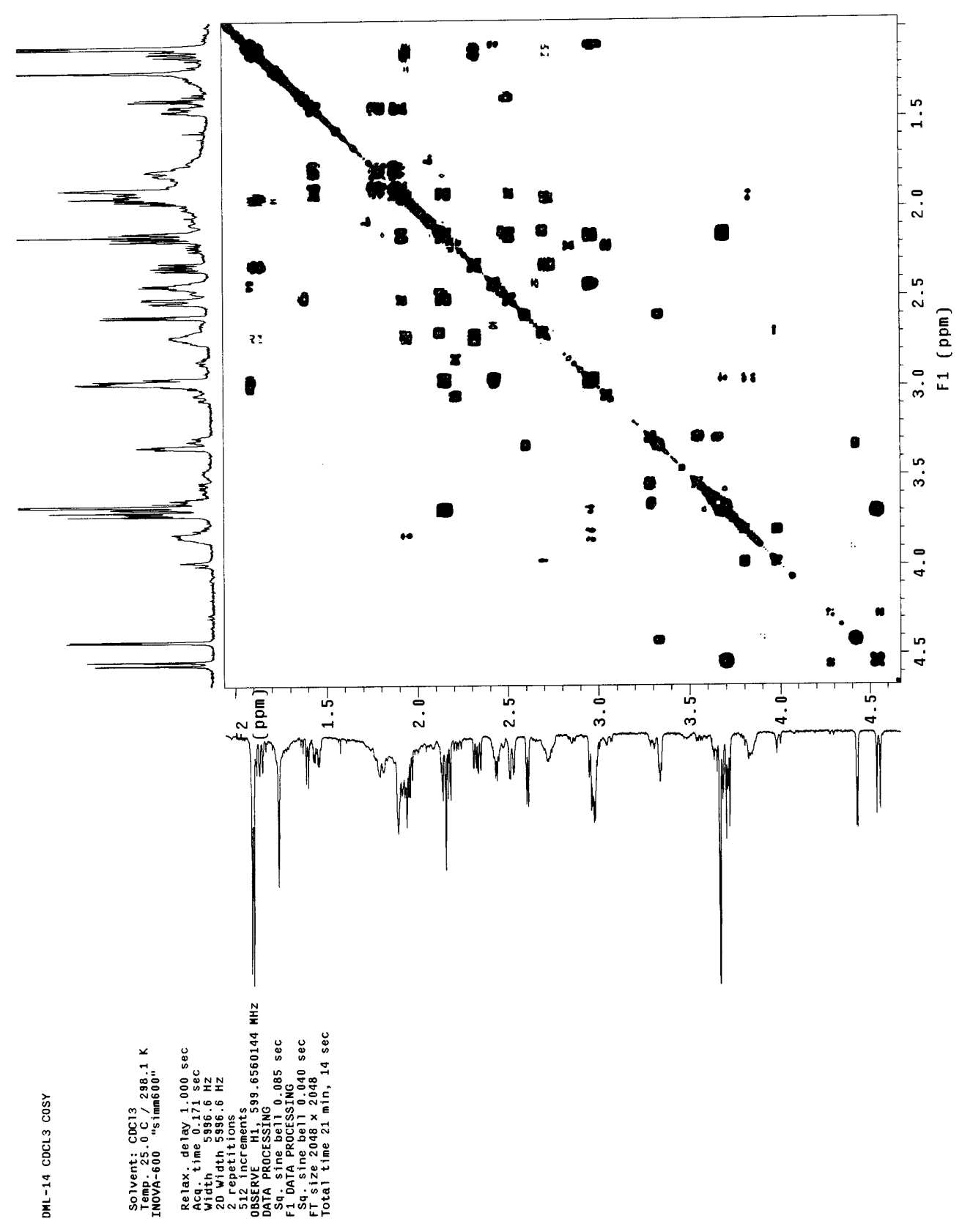


${ }^{1} \mathrm{H}-{ }^{1} \mathrm{H}$ COSY spectrum of Macropodumine D (1) in $\mathrm{CDCl}_{3}$ (Enlarged)
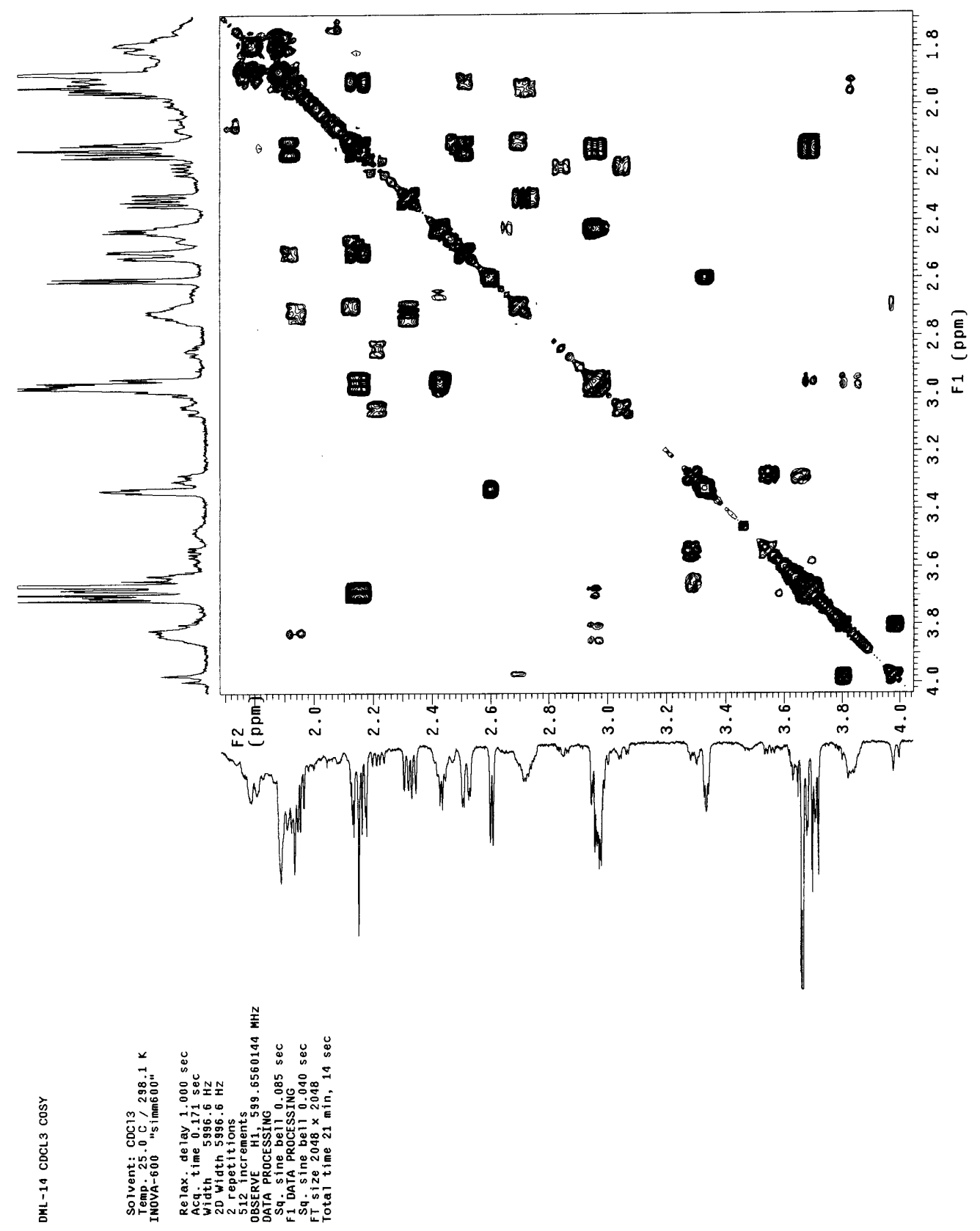
HSQC spectrum of Macropodumine D (1) in $\mathrm{CDCl}_{3}$
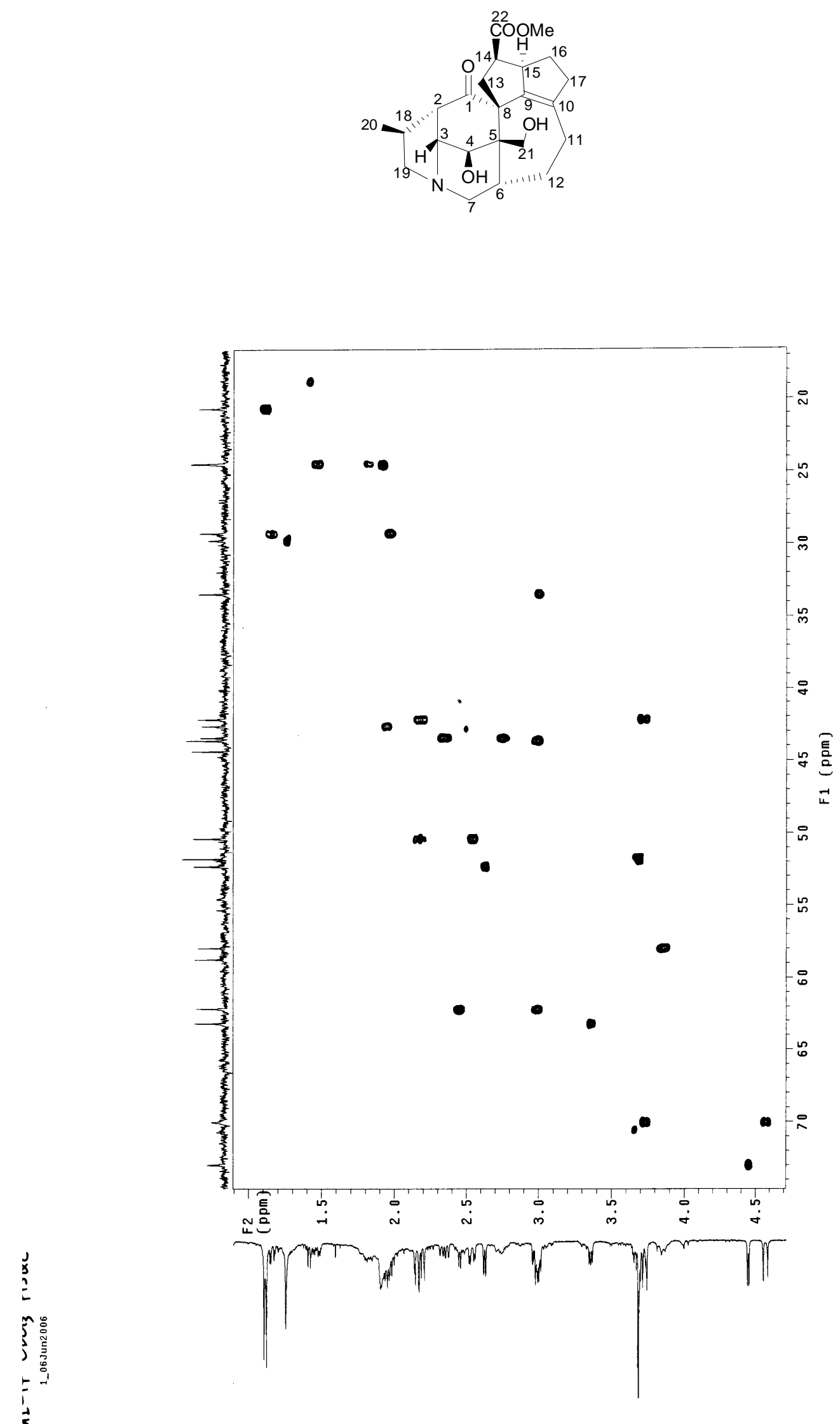

11 
HMBC spectrum of Macropodumine D (1) in $\mathrm{CDCl}_{3}$
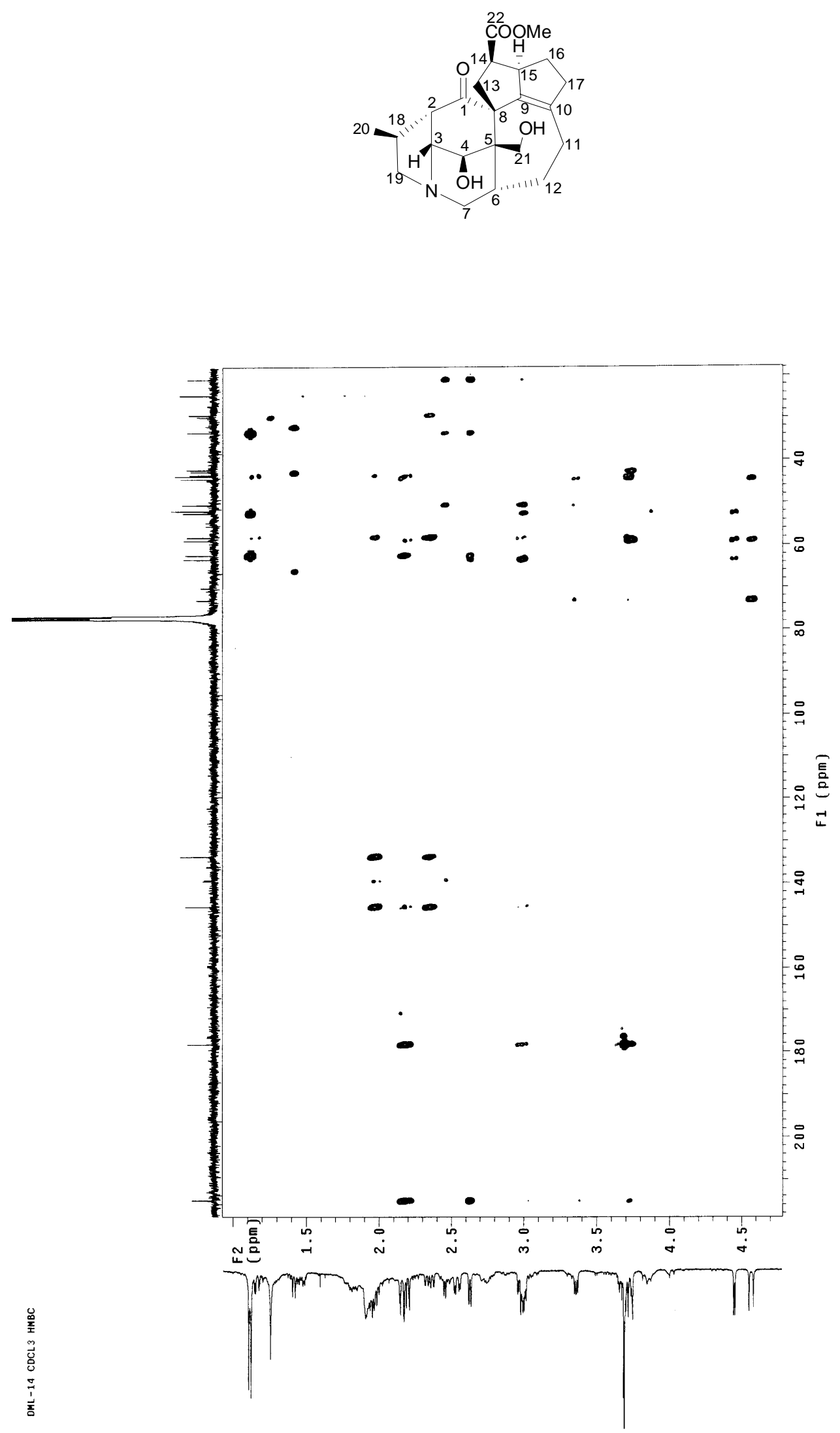
HMBC spectrum of Macropodumine D (1) in $\mathrm{CDCl}_{3}$ (Enlarged)

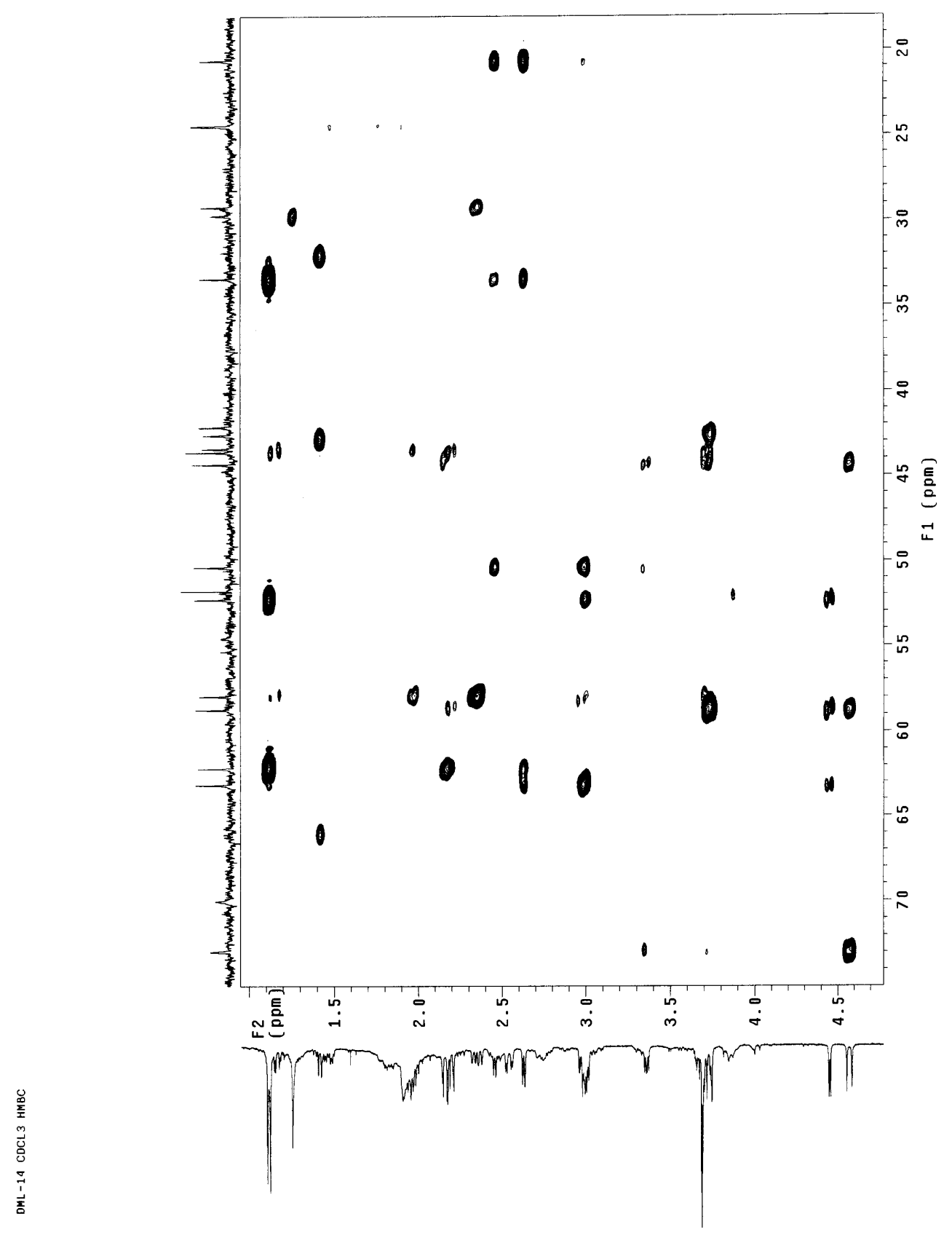


ROESY spectrum of Macropodumine D (1) in $\mathrm{CDCl}_{3}$

$$
20
$$

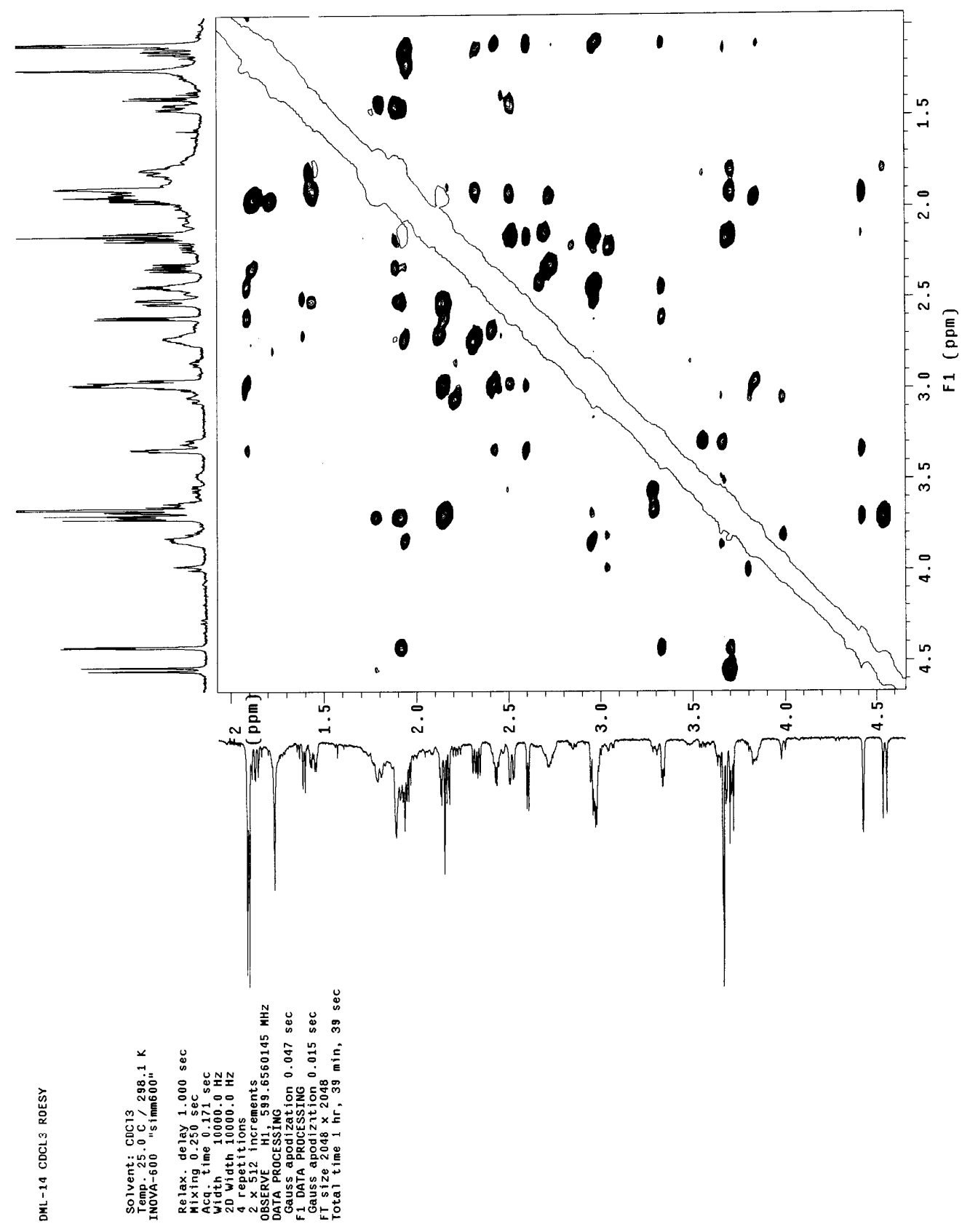


ROESY spectrum of Macropodumine D (1) in $\mathrm{CDCl}_{3}$ (Enlarged)

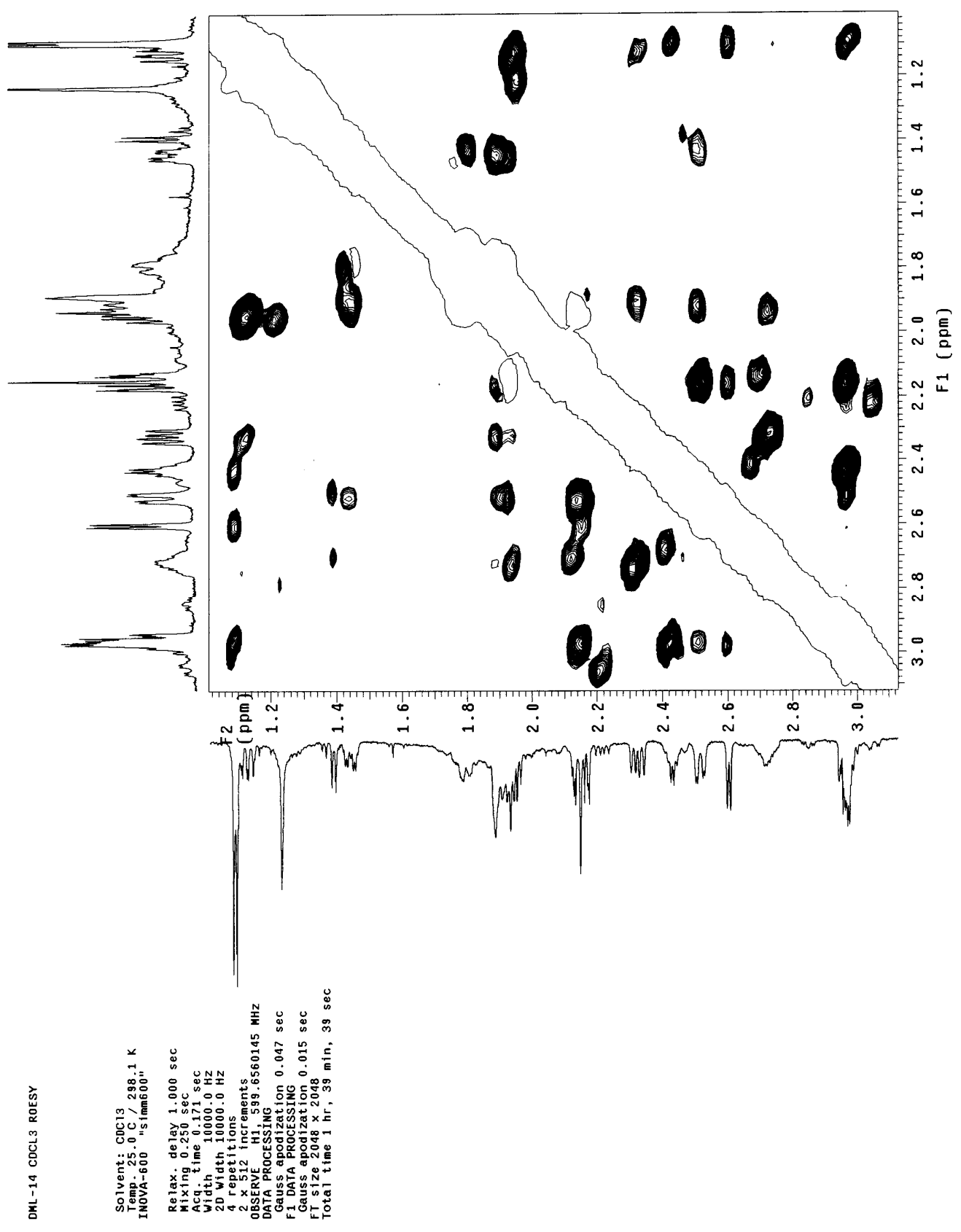

15 
HR-ESIMS spectrum of Macropodumine E (2)
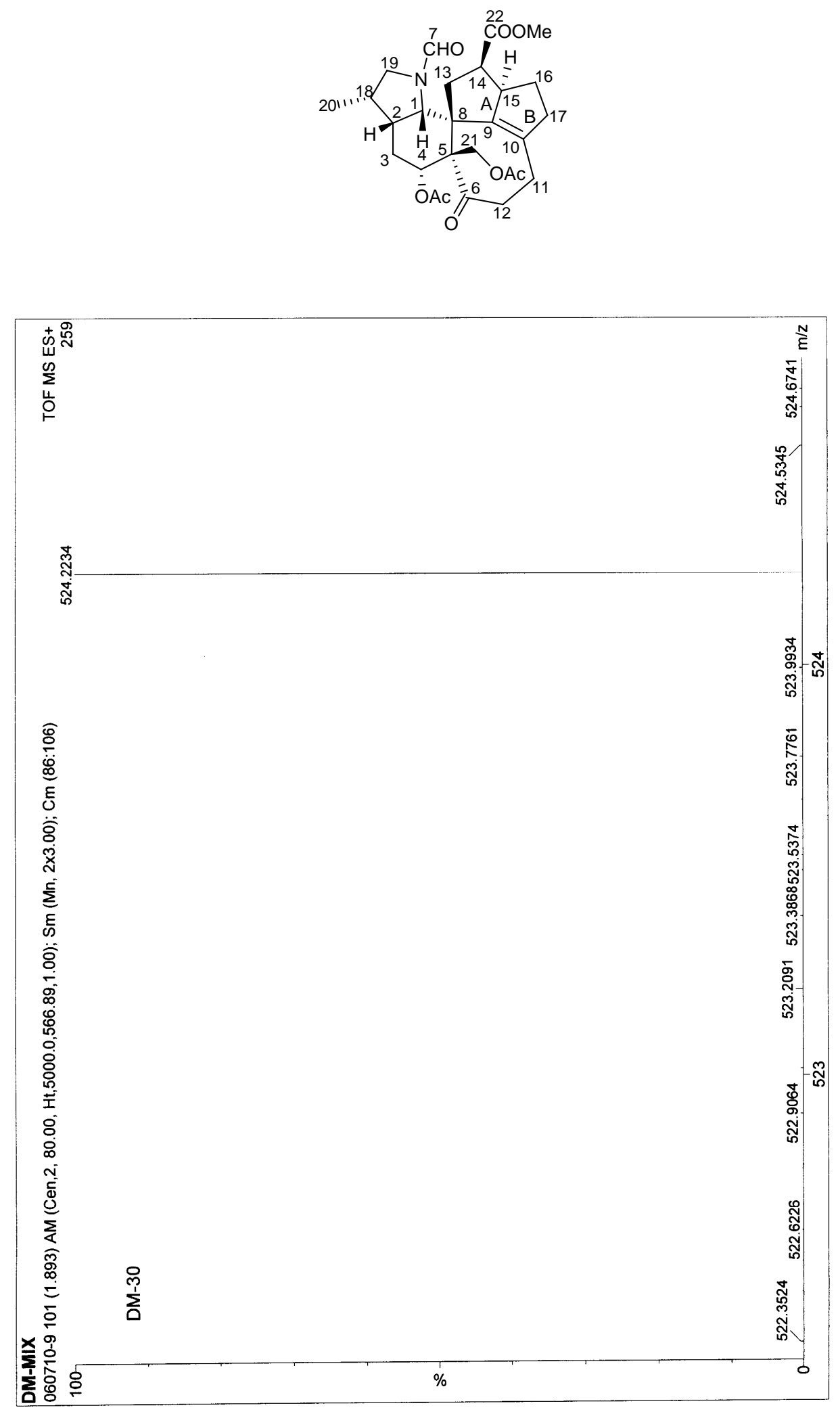
HR-ESIMS spectrum of Macropodumine E (2) (Continued)

Elemental Composition Report

Page

Tolerance $=20.0$ PPM / DBE: $\min =-1.5, \max =50.0$

Isotope cluster parameters: Separation $=1.0$ Abundance $=1.0 \%$

Monoisotopic Mass, Odd and Even Electron lons

40 formula(e) evaluated with 1 results within limits (up to 20 closest results for each mass)

DM-MIX

060710-9 101 (1.893) AM (Cen, 2, 80.00, Ht,5000.0,566.89,1.00); Sm (Mn, 2×3.00); Cm (86:106)

100

\%

$-$

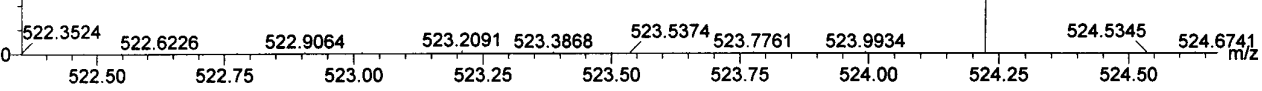

Minimum: $\quad 30.00$

Maximum: $\quad 100.00$

$200.0 \quad 20.0 \quad 50.0$

Mass RA Calc. Mass mDa PPM DBE

Score Formula

$524.2234 \quad 100.00 \quad 524.2260$

$-2.6 \quad-5.0$

$10.5 \quad 1$

$\begin{array}{lllll}\mathrm{C} 27 & \mathrm{H} 35 & \mathrm{~N} & 08 & \mathrm{Na}\end{array}$ 
${ }^{1} \mathrm{H}$ NMR spectrum of Macropodumine $\mathrm{E}(2)$ in $\mathrm{CDCl}_{3}$
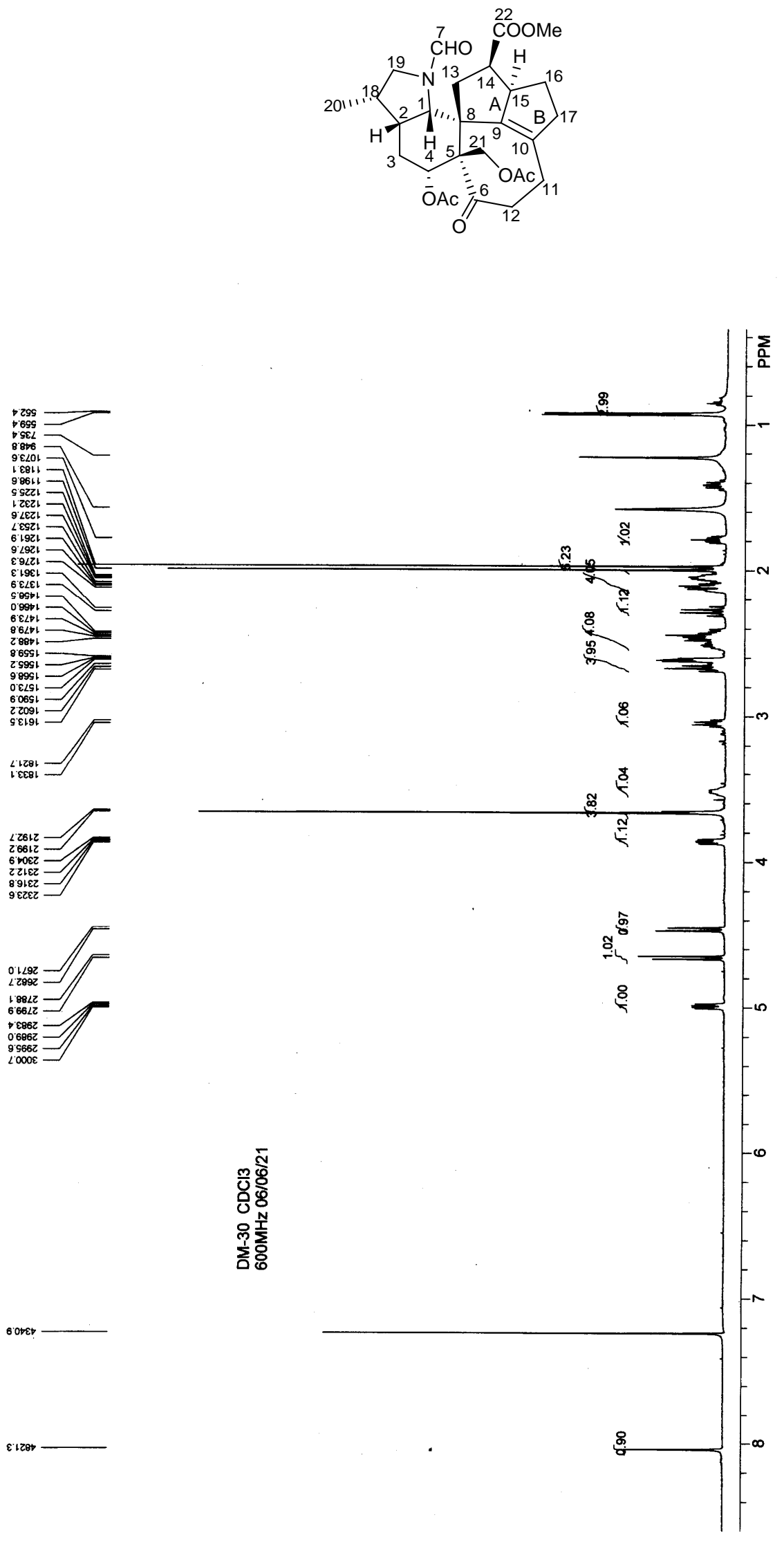
${ }^{13} \mathrm{C}$ NMR spectrum of Macropodumine $\mathrm{E}(2)$ in $\mathrm{CDCl}_{3}$
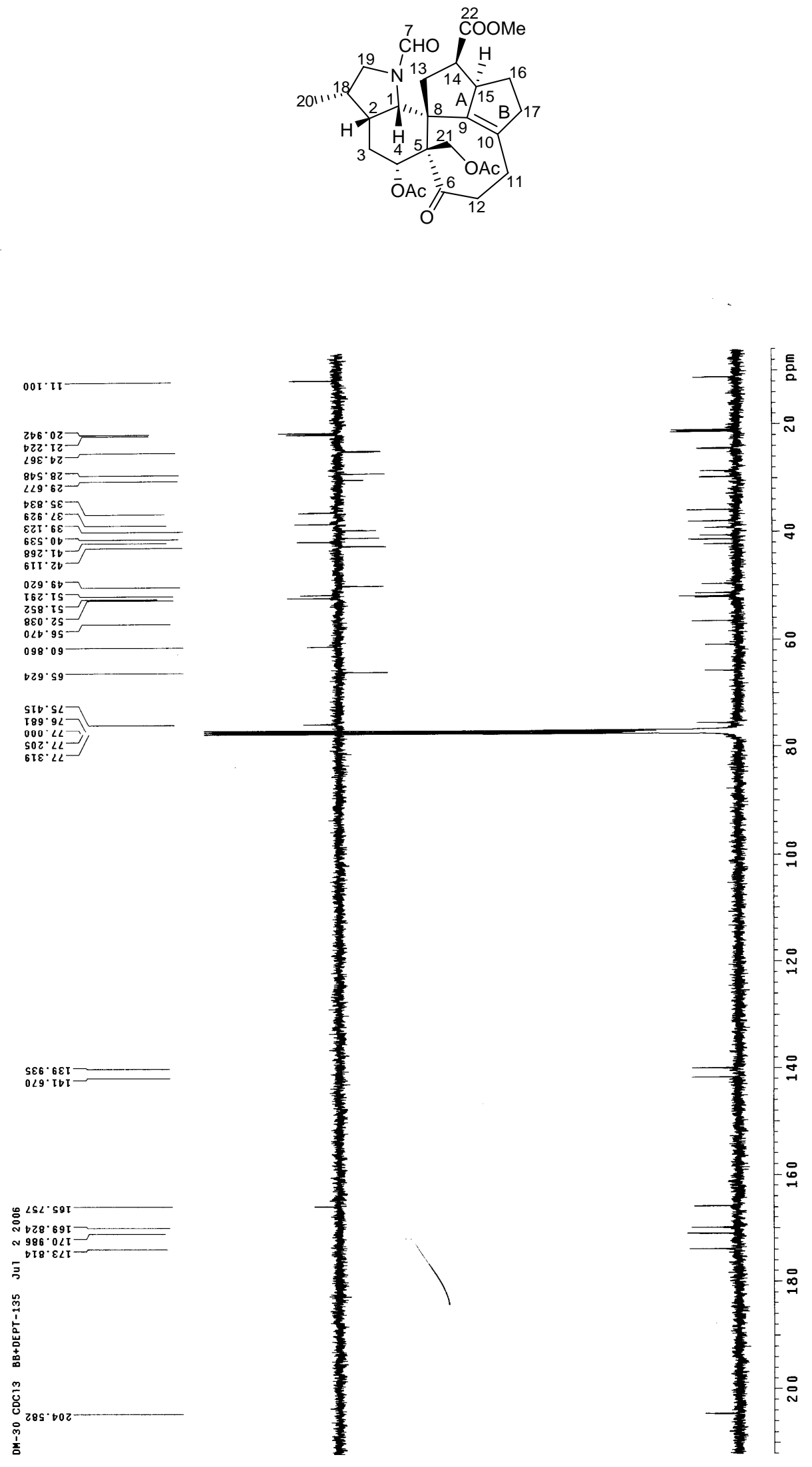
${ }^{13} \mathrm{C}$ NMR spectrum of Macropodumine $\mathrm{E}$ (2) in $\mathrm{CDCl}_{3}$ (Enlarged)
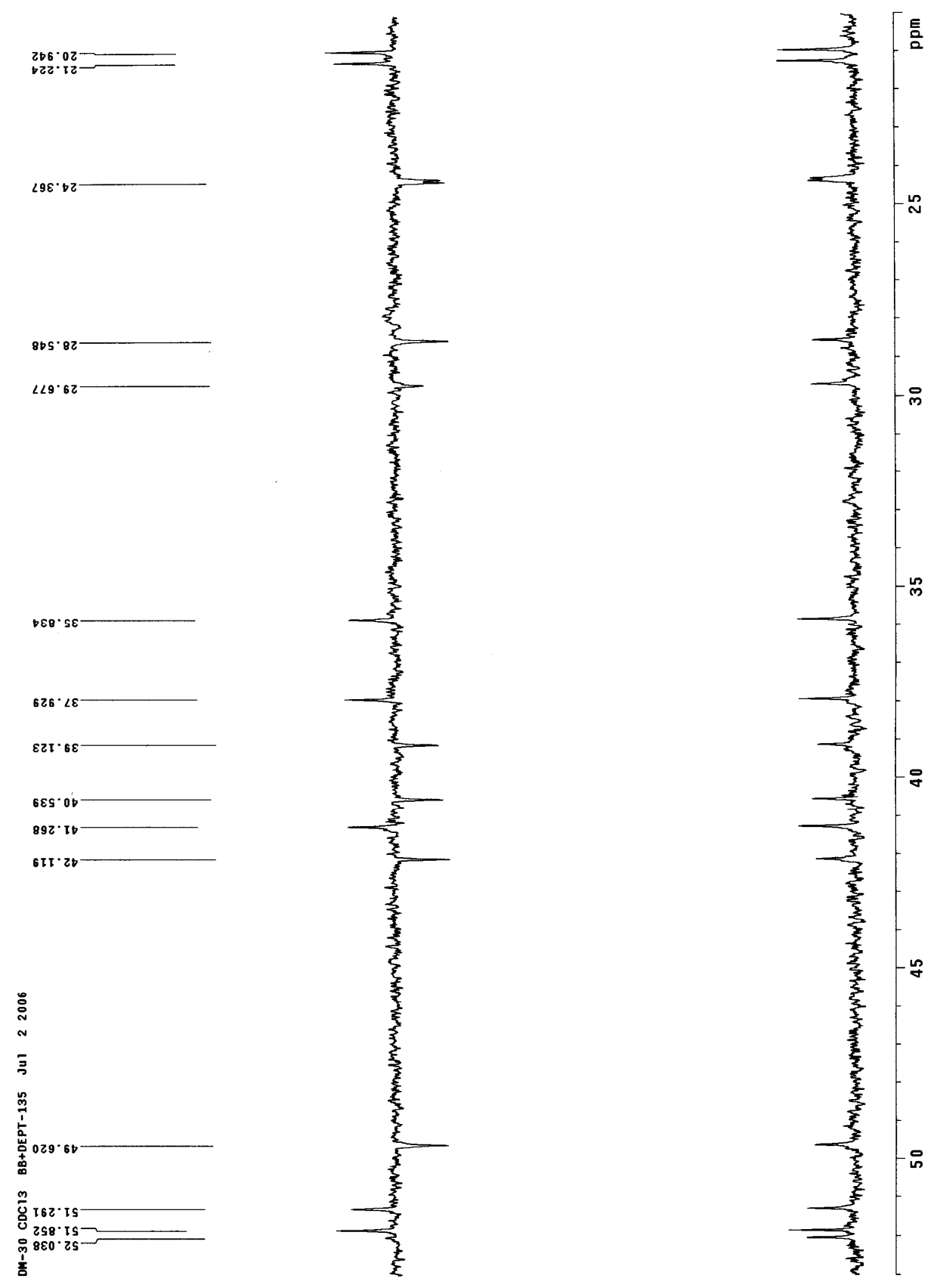
${ }^{1} \mathrm{H}-{ }^{1} \mathrm{H}$ COSY spectrum of Macropodumine E (2) in $\mathrm{CDCl}_{3}$
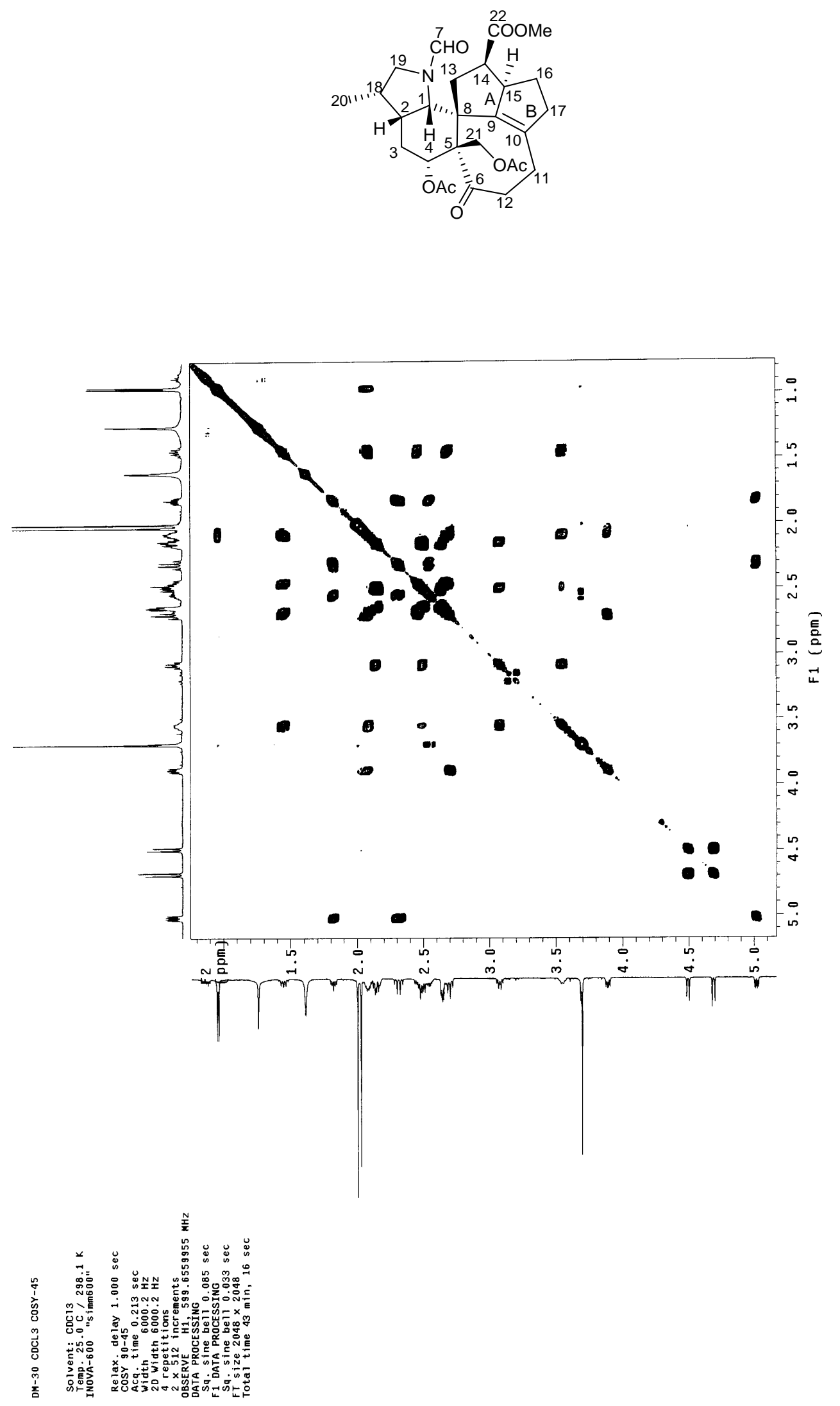
${ }^{1} \mathrm{H}-{ }^{1} \mathrm{H}$ COSY spectrum of Macropodumine E (2) in $\mathrm{CDCl}_{3}$ (Enlarged)

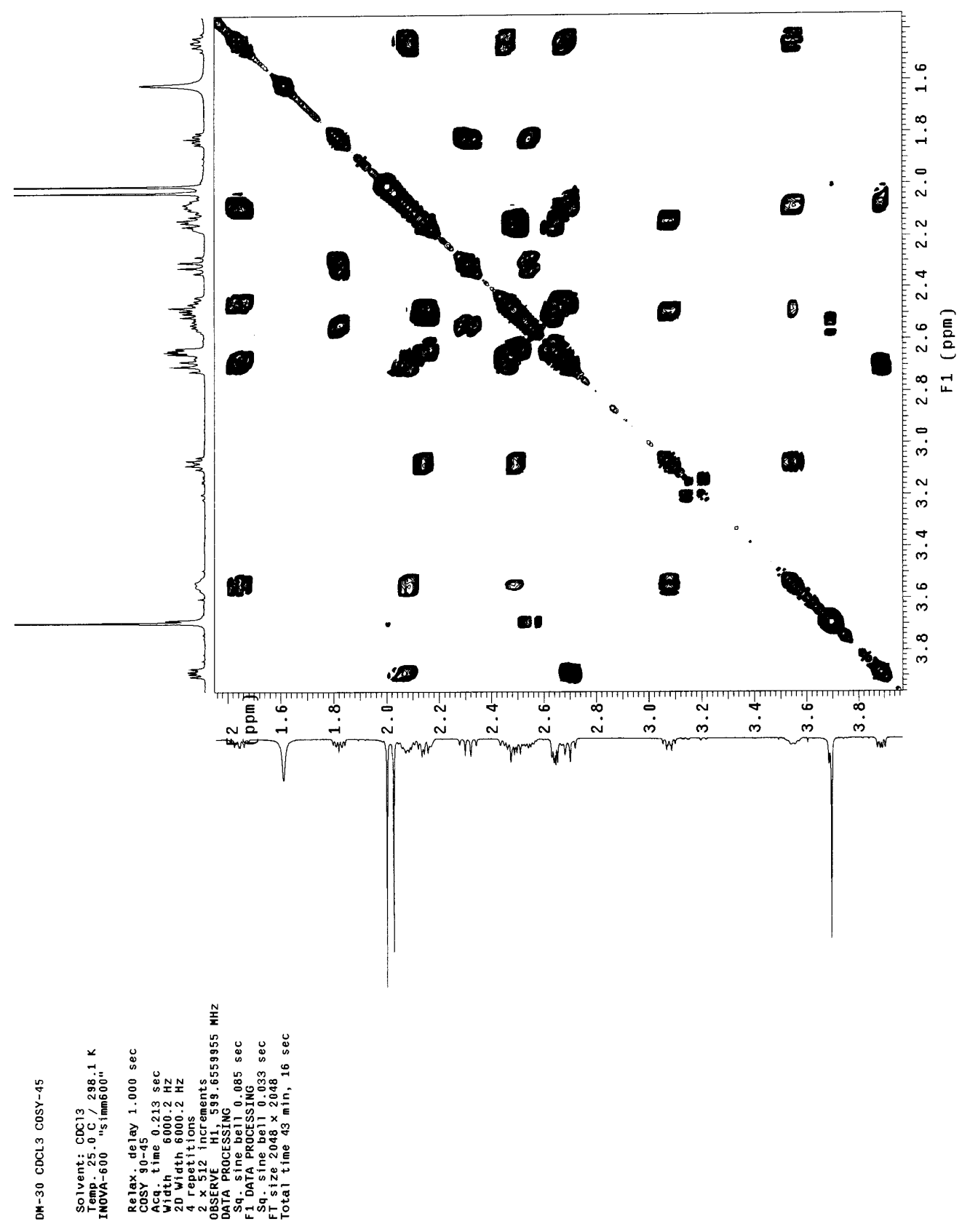


HSQC spectrum of Macropodumine E (2) in $\mathrm{CDCl}_{3}$
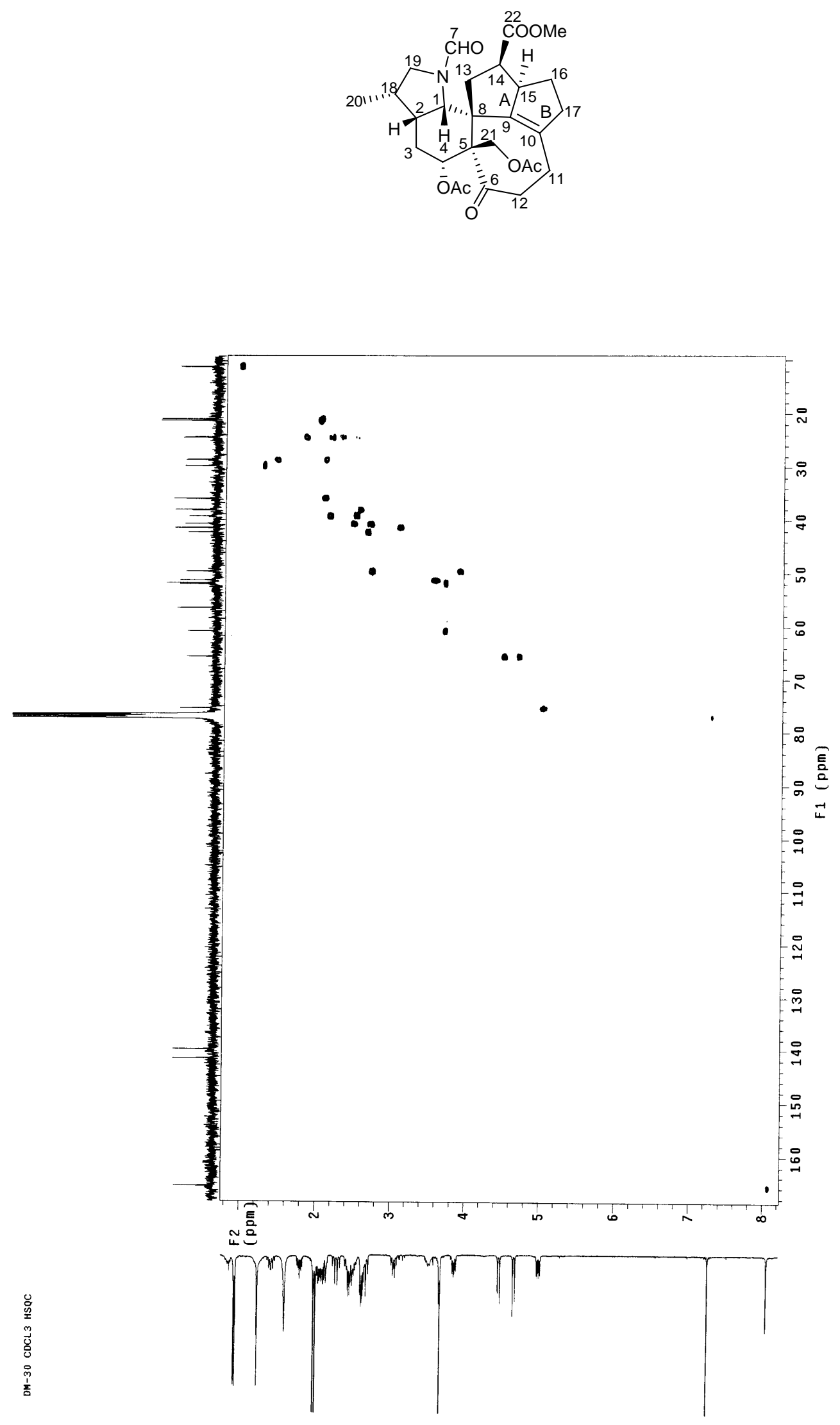
HSQC spectrum of Macropodumine E (2) in $\mathrm{CDCl}_{3}$ (Enlargd)

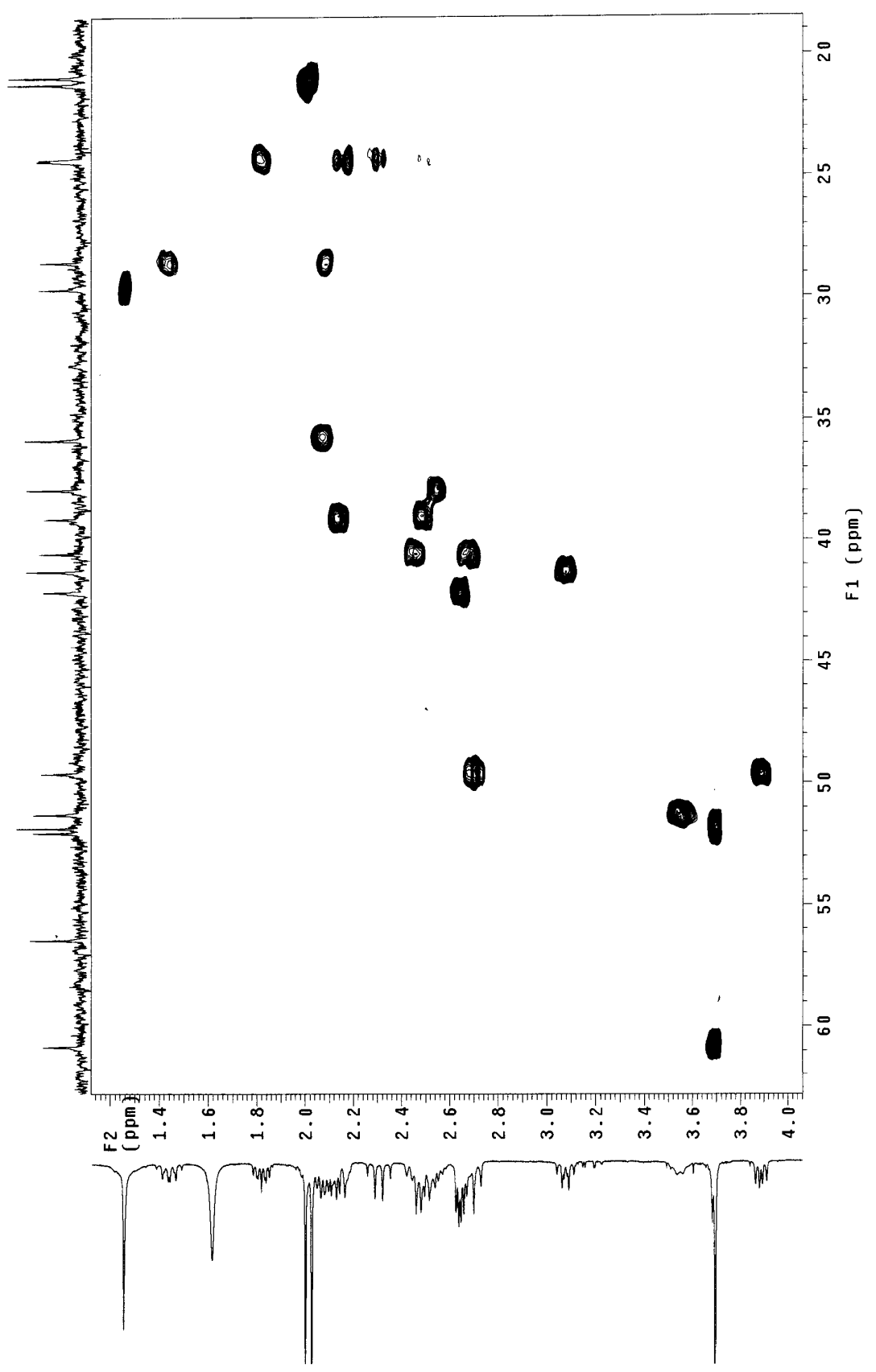


$\mathrm{HMBC}$ spectrum of Macropodumine $\mathrm{E}$ (2) in $\mathrm{CDCl}_{3}$
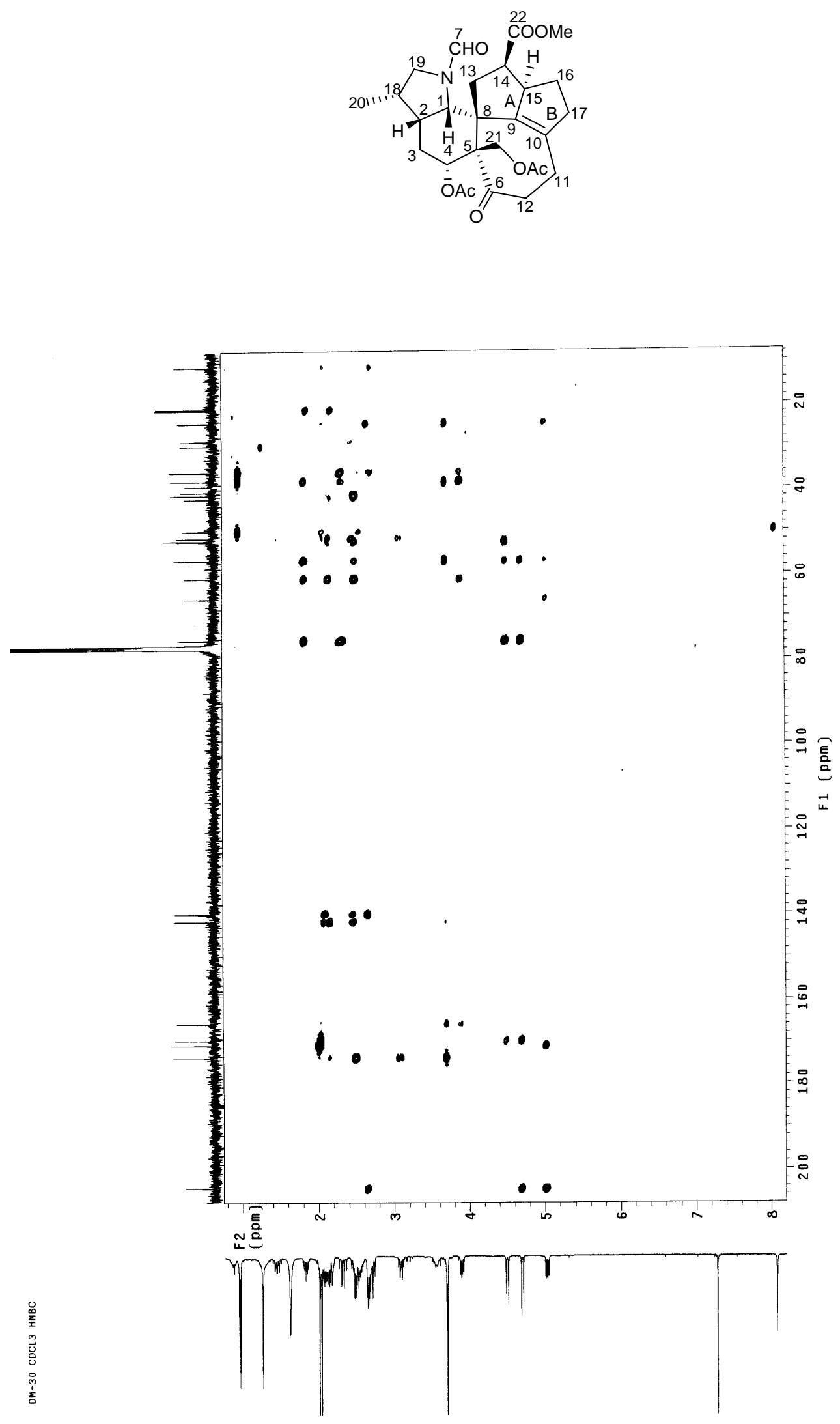
HMBC spectrum of Macropodumine E (2) in $\mathrm{CDCl}_{3}$ (Enlarged 1)

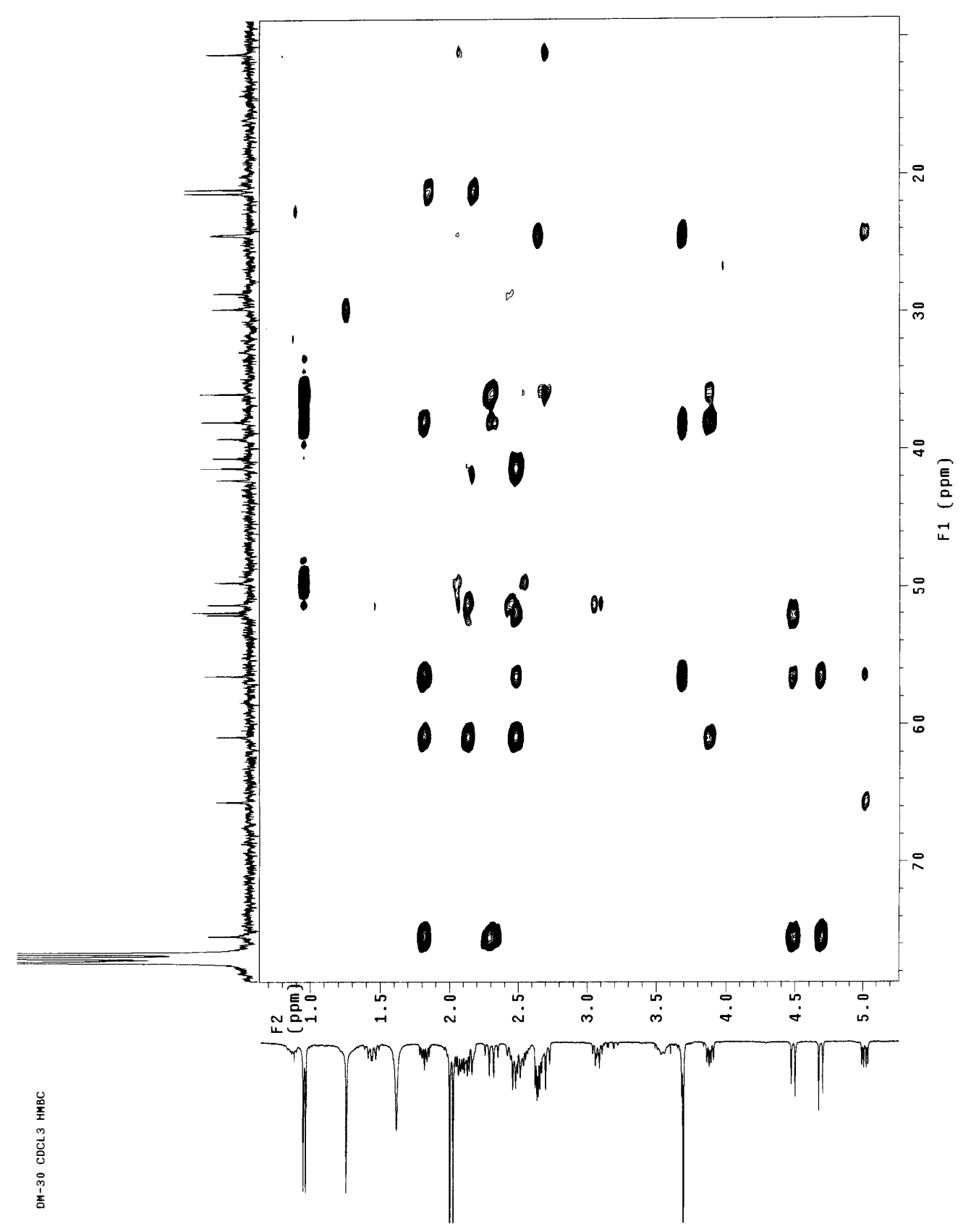


HMBC spectrum of Macropodumine E (2) in $\mathrm{CDCl}_{3}$ (Enlarged 2)

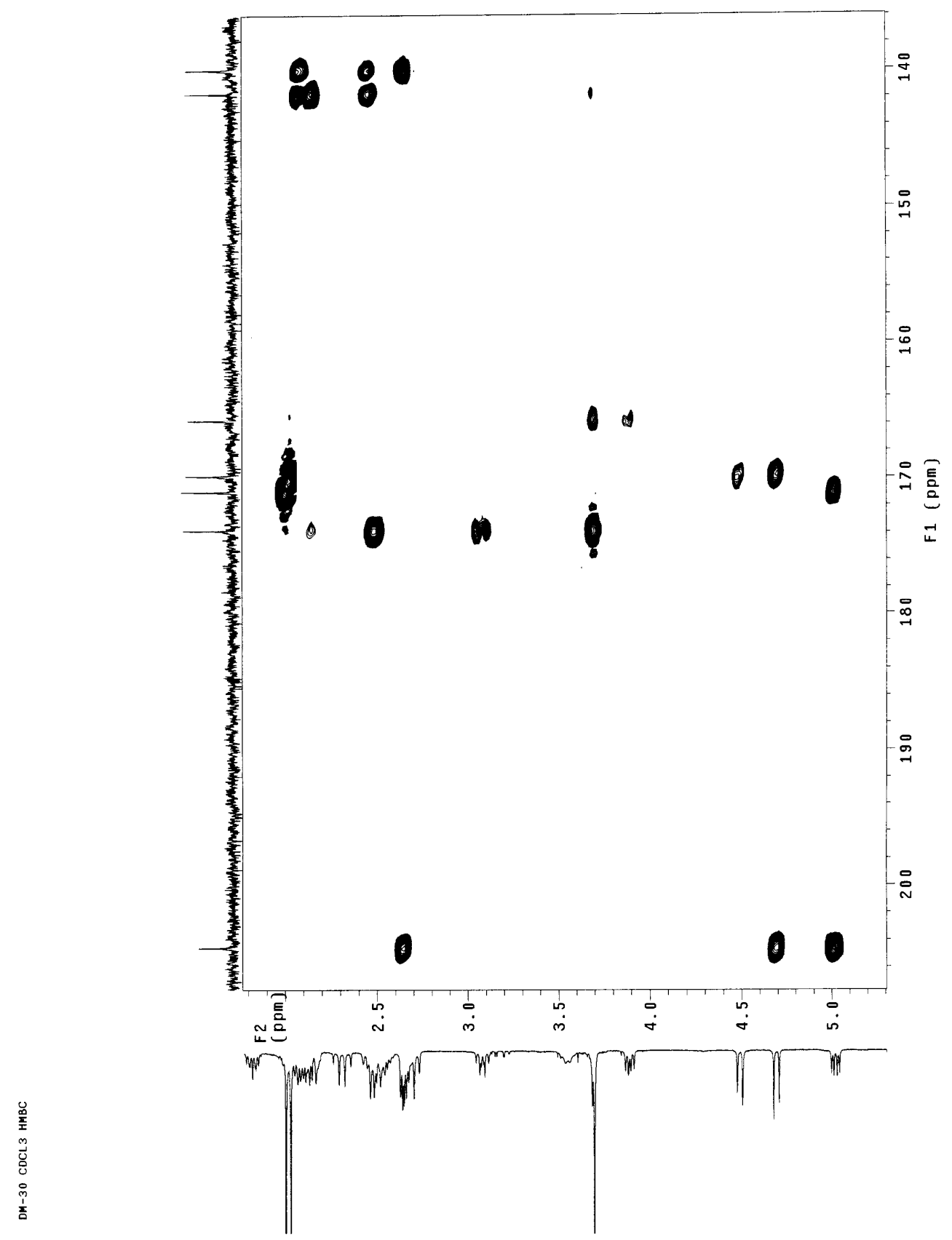


ROESY spectrum of Macropodumine E (2) in $\mathrm{CDCl}_{3}$

$$
\text { (19) }
$$

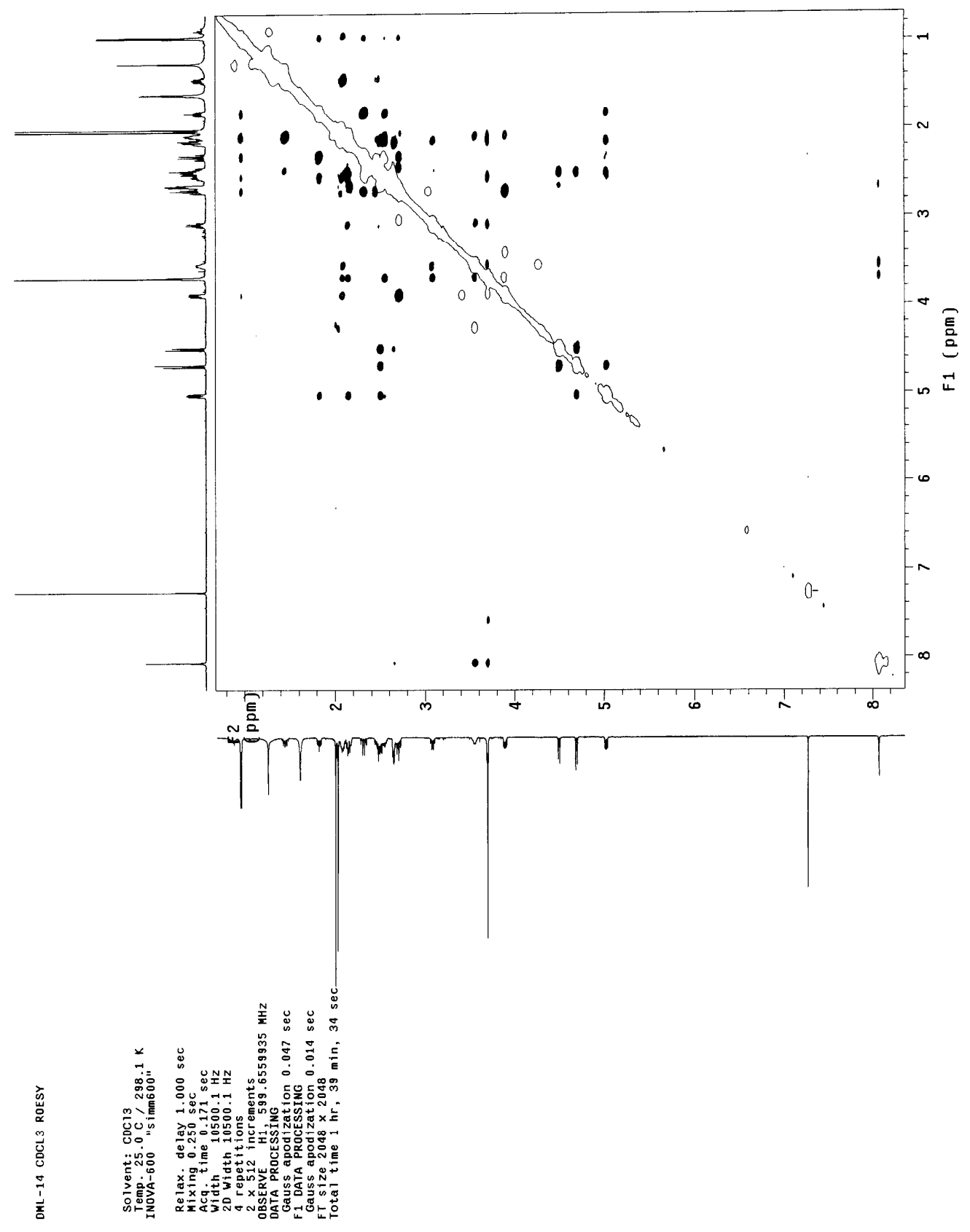


ROESY spectrum of Macropodumine E (2) in $\mathrm{CDCl}_{3}$ (Enlarged)

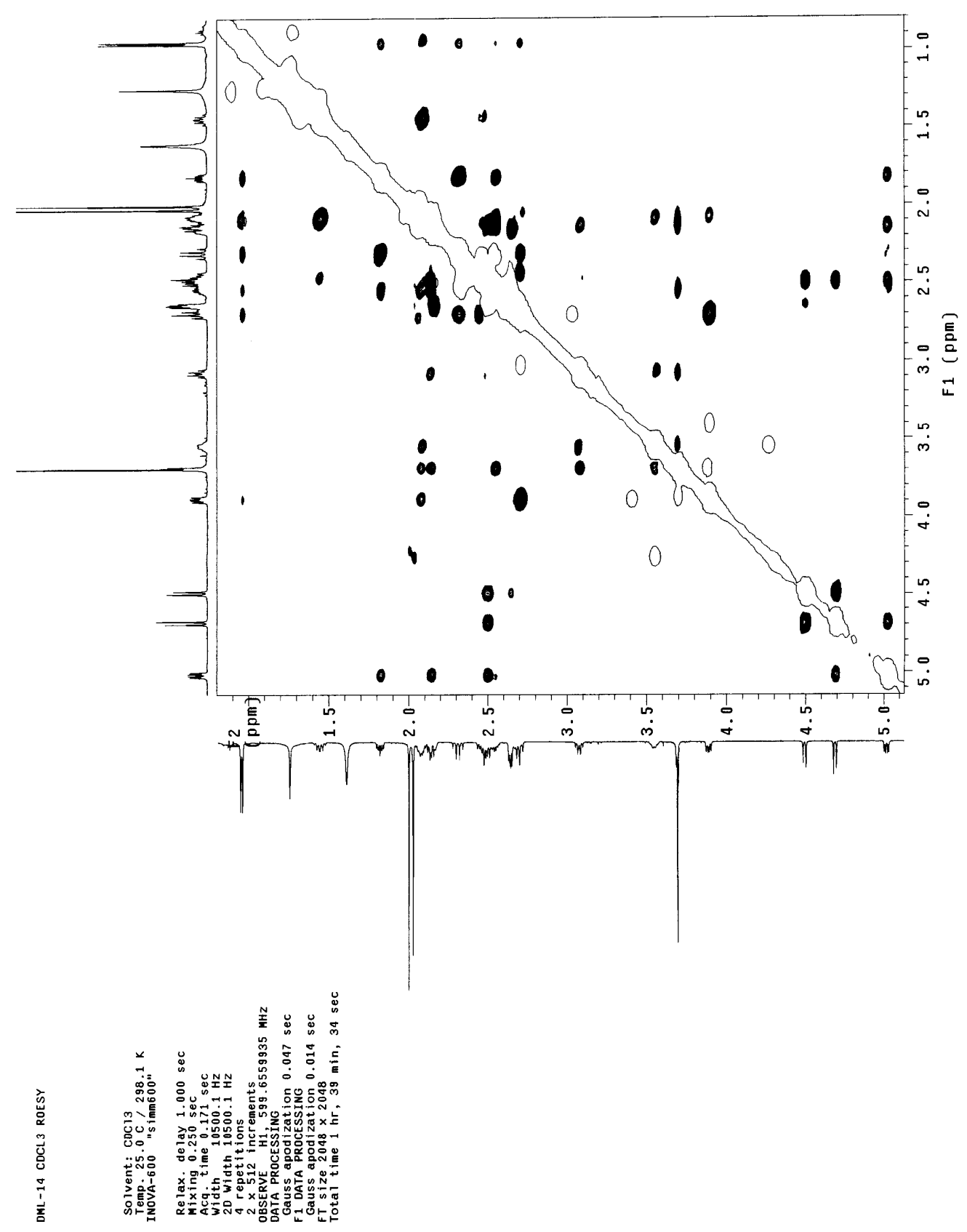

